of the ester of oocyan indicated a molecule with only three pyrrol nuclei, the analysis and methoxyl content of the methyl ester of uteroverdin (as we will call the substance) show that we are dealing with a substance with four pyrrol nuclei. From its composition $\left(\mathrm{C}_{35} \mathrm{H}_{38-42} \mathrm{~N}_{4} \mathrm{O}_{6}\right)$ it appears that it is the dimethyl ester of a dehydrobilirubin or dehydromesobilirubin. The values for $\mathrm{C}, \mathrm{H}$, and $\mathrm{N}$ (not, however, the methoxyl content) of the ester of oocyan agree also with the formula $\mathrm{C}_{37} \mathrm{H}_{42} \mathrm{~N}_{4} \mathrm{O}_{8}$; that is to say, with that of the trimethyl ester of a substance which differs from uteroverdin only in possessing one more carboxyl group. A further investigation of oocyan by one of us (R. L.) is in progress.

Oocyan differs from the synthetic tripyrrenes of $\mathrm{H}$. Fischer ${ }^{4}$ in its absorption and in giving a clearly positive Gmelin reaction. Attempts are being made to pass from bilirubin to this new class of substances, to which probably belong one or other of the green oxidation-products of bilirubin, obtained by very different methods, hitherto considered to be 'biliverdin'.

We do not know yet what is the significance of the fact that the decomposition of hæmoglobin in the dog's placenta-and in other cases of blood extravasates in the uterus-leads to such pigments instead of to bilirubin. It has not, up to the present, been possible to demonstrate an enzymic formation of uteroverdin by placenta tissue or tissue extract, any more than in the case of bilirubin.

R. Lemberg.

J. BARCROFT.

D. KEILIN.

Biochemical and Physiological Laboratories and Molteno Institute, Cambridge.

1 R. Lemberg, Liebigs Ann., 488, 74 ; 1931.

Etti, Malys.Jahresherichte, p. 233; 1871: p. $287 ; 1872$

3 On the histological findings, see B. Schick, Zeit. für Kinderheil. Lunde, 28, 231; 1921 . N. Lieberkühn and H. Strahl, Arch. für dnat. und Physiol., p. $196 ; 1889$.

'H. Fischer and E. Adler, Zeit. für physiol. Chem., 200, 209 ; 1931.

\section{Properties of Aerosols.}

Messrs. W. Cawood and H. S. Patterson's letter ${ }^{1}$ describing "A Curious Phenomenon shown by Highly Charged Aerosols " is very interesting from the viewpoint of spontaneously electrified aerosols, as well as from that of aerosols electrically charged from an independent source such as they used.

The work of W. A. D. Rudge, ${ }^{2}$ showing that most aerosols initiate static charges owing to the movement of the constituent particles through the gaseous dispersion medium, has led to the theory of A. Stager, ${ }^{3}$ who experimented with driven snow-dust on the Jungfrau, that in a spontaneously charged aerosol the smaller particles become charged in one sense and the larger ones in the other sense. On a priori grounds this theory does not seem capable of satisfying the facts save where the disperse phase of an aerosol consists of particles of but two sizes. For, where particles of several sizes were involved, any dimension except the smallest and largest would be both 'larger' and 'smaller' by alternative relation with respectively juxtaposed sizes. On the other hand, the phenomenon observed by Messrs. Cawood and Patterson seems to confirm selectivity of chargesign dependent on variation in particle size in so far as electrification due to an independent source can be compared with self-electrification of an agitated aerosol.

In Messrs. Cawood and Patterson's experiments both types of electrification would, presumably, exist, and although one does not know what degree of spontaneous electrification would arise on, say, $p$ xylene-azo- $\beta$-napthol under the conditions they imposed (Blacktin and Robinson ${ }^{4}$ find that $0.0011 \mathrm{oz}$. av. per cubic foot of coal dust of fineness 83.5 per cent through 200 I.M.M. sieve, whirled at 45 feet per second, rapidly initiates a potential of more than 4000 volts), it may well be that 'clusters' might be formed in their chamber, $(a)$ merely on fanning without independent electrification, or $(b)$ partially due to the additional spontaneous electrification as a significant superposed factor. If the former proved correct, a great step would have been taken in establishing the sign-particle size theory of spontaneous electrification in aerosols.

It may be worthy of note that if, as Messrs. Cawood and Patterson suggest, globular lightning may owe its origin to an effect analogous to the phenomenon they observe, the "very much higher potential" involved would be of spontaneous, rather than inde. pendent, origin. This would be a tentative reason for expecting the phenomenon they observed to show itself as producible merely through controlled spontaneous electrification without the necessity for introducing an independent source of electrification.

1 Adelaide Road,

S. C. Blacktin.

Andover, Hants, Nov. 5.

1 NAture, 128, 150, July 25, 1931.

2 Phil. Maq., 25, 481; 1913.

3 Ann. der Physik, 76, 49; 1925.

- Safety in Mines Research Board, Paper No. 71. London: Н.М. Stationery Office.

\section{Garbon Gontacts.}

IN his delightful article on the Hope-Jones clock, in Nature of Oct. 17, Prof. Boys refers to the difficulty of obtaining sure and certain contact for electrical purposes with light pressure. This difficulty may be overcome by using carbon contacts. I have had a station voltage regulator in operation for some twenty years with carbon contacts and the result has been quite satisfactory, the carbon being pure and free from ash. The microphone provides another instance of such contact operated in circumstances which are delicate. Probably there are many instances in the laboratory where carbon contacts for working apparatus through relays would be of service.

Electricity Works,

North Shields, Oct. 31.

THE contact difficulties to which I referred were those of fifty years ago with light or hesitating contacts backed by insufficient volts. I did not intend to imply that at the present time with new materials and abundant volts contacts need give any trouble. I have for a long time recommended Acheson graphite made at Niagara, from which all other matter has been volatilised, and this, I expect, is what Mr. Turnbull has used. There are also the more modern mercury in nitrogen contacts which are admirable where the larger movement necessary to operate them and the slight time delay do not matter.

Where there is much self induction in the circuit to be broken, plenty of capacity as a shunt across the break is desirable, and thanks to wireless dealers this can now be obtained for fewer shillings than the cost in pounds at the earlier date. I used at Oxford when weighing the earth in place of a capacity a pair of electrolytic cells in series with platinum electrodes which I still have, the current coming from a pair of secondary cells. At each break every second a bunch of microscopic bubbles of the electrolytic gases were evolved, but the spark was absolutely quenched. Such a device is the electrical analogue of the water ram. Not one contact ever failed. I consider it better than a true capacity.

$$
\text { No. } 3240 \text {, VoL. 128] }
$$

